\title{
A validated UPLC method for the determination of process- related impurities in Antimigraine bulk drug
}

\author{
N.Balaji ${ }^{1}$, V.R.Sivaraman ${ }^{1}$, Dr.P. Neeraja ${ }^{2}$ \\ ${ }^{I}$ (Department of Analytical chemistry, Dravidian University, Kuppam, India) \\ ${ }_{2}^{2}$ (Department of chemistry, Adhiyamaan engineering college, Anna University, Hosur, India)
}

\begin{abstract}
An UPLC method has been developed and subsequently validated for the determination of antimigraine drug and its process-related impurities. Separation was achieved with Halo C18, 50x $4.6 \mathrm{~mm}$, $2.7 \mu \mathrm{m}$ column and $1.36 \mathrm{~g}$ ofmonobasic potassium phosphate in $1000 \mathrm{~mL}$ of water with $2 \mathrm{~mL}$ of triethylamine at pH 6.8 using $\mathrm{H}_{3} \mathrm{PO}_{4}$, acetonitrile and methanol in the ratio of $55: 38: 7$ as eluent in isocratic mode. Flow rate was set as $1 \mathrm{~mL} \cdot \mathrm{min}^{-1} \mathrm{UV}$ detection was performed at $225 \mathrm{~nm}$. The method was validated with respect to specificity, accuracy, precision, linearity, robustness, limit of quantification and limit of detection. The accuracy of the method demonstrated at three levels in the range of 50-150\% of the specification limit and the recovery of impurities were found to be in range of 98 to 102\%. The detection limits of the process related impurities ranged between 0.16 and $0.24 \mu \mathrm{gmL}^{-1}$. The described method is simple, rapid, linear, precise, accurate, robust and stability indicating. The method is useful during process development and quality of bulk manufacturing.
\end{abstract}

Keywords: Ultra performance liquid chromatography (UPLC), Antimigrainedrugs, Validationand Process related impurities.

\section{Introduction}

Eletriptan hydrobromide is a novel, orally active, selective serotonin 5-HT1B/1D receptor agonist and is second generation anti-migraine drug. Eletriptan hydrobromide is chemically designated as (R)-3-[(1-methyl2-pyrrolidinyl) methyl]-5-[2-(phenylsulfonyl) ethyl]-1H-indoleMonohydrobromide. Eletriptan hydrobromide used for the treatment of acute migraine headaches. Its pharmacological effects include the constriction of cerebral blood vessels and neuropeptides secretion blockade which eventually relieves the pain. The pharmacokinetics and metabolism of Eletriptan hydrobromide have been investigated in the rat, dog and human. In all three species, Eletriptan hydrobromide was rapidly absorbed and extensively cleared by metabolism. The pathways of Eletriptan metabolism are similar in the rat, dog and human and principal routes include pyrrolidine $\mathrm{N}$-demethylationto $\mathrm{N}$-desmethyl Eletriptan, together with $\mathrm{N}$-oxidation, oxidation of the pyrrolidine ring and formation of tetra cyclic quaternary ammonium metabolites.

A few methods are reported in the literature for the analysis of drugs by HPLC [1-7], LC-MS [8-10], MS-MS [11], spectrometric [12-16] and TLC [17]. UPLC is a new category of separation science which builds upon well-established principlesof liquid chromatography, using sub- $2 \mu \mathrm{m}$ porous particles. These particles operate at elevated mobilephase linear velocities to produce rapid separation with increased sensitivity and increased resolution.

In this study, Eletriptan hydrobromide is selected from antimigraine category of drugs. The objective of this work was to develop and validate a stability indicating UPLC method forthe determination of process related impurities in Eletriptan hydrobromide.

\subsection{Chemicals}

\section{Experimental Data}

Jiangsu Pharma limited (China) kindly supplied samples of Eletriptan hydrobromide and its processrelated impurities (Table 1). HPLC grade acetonitrile, HPLC grade methanol, monobasic potassium phosphate, orthophosphoric acid and triethylamine were purchased from Merck (India). Sodium hydroxide (NaOH), Hydrochloric acid $(\mathrm{HCl})$ and Hydrogen peroxide $\left(\mathrm{H}_{2} \mathrm{O}_{2}\right)$ were obtained from Fisher Scientific (Mumbai, India).High purity water was obtained by Siemens Ultra clear water purification system. Solvents, mobile phase components and all required solutions were filtered through $0.22 \mu$ syringe filter purchased from Millipore, India.

\subsection{Equipment}

A Waters Acquity UPLC system equipped with binary solvent delivery pump, an auto sampler, a column oven and diode array detector was utilized for method development and validation. The output signal was monitored and processed using Empower software. 
Cintex digital water bath was used for acid and base hydrolysis studies. Photostability studies were carried out in a Sanyo Photostability chamber (Leicestershire, UK). Thermal stability studies were performed in a dry air oven from Thermo (Mumbai, India).

\subsection{Sample preparation}

\subsubsection{Test solution}

The test solution of $1.0 \mathrm{mg} \mathrm{mL}^{-1}$ was prepared in diluent (methanol) and injected inthe system for the test of determination of related impurities in Eletriptan hydrobromide bulk drug.

\subsubsection{Solution for determination of relative response factor}

The blend solution containing $5 \mu \mathrm{g} \mathrm{mL} L^{-1}$ concentration of Eletriptan hydrobromide and each impurity was prepared in methanol. Thissolution was used for the determination of relative response factor of all the impurities.

\subsubsection{Validation solution}

The solution of $10 \mu \mathrm{g} \mathrm{mL}^{-1}$ concentration for each impurity separately as well as blend solution was prepared. These two solutions were used as stock solution to prepare validation solutions.

\subsection{Chromatographic conditions}

A Halo C18 analytical column $(50 \mathrm{~mm} \times 4.6 \mathrm{~mm}, 2.7 \mu \mathrm{m})$ was used for analysis at $30^{\circ} \mathrm{C}$. The bufferwas prepared asdissolved $1.36 \mathrm{~g}$ of monobasic potassium phosphate in $1000 \mathrm{~mL}$ of water, added $2.0 \mathrm{~mL}$ of triethylamine and adjusted the $\mathrm{pH}$ to 6.8 with orthophosphoric acid. The mobile phase consisted of buffer, acetonitrileand methanol in the ratio of $55: 38: 7$ in isocratic mode and was pumped through the column at a flowrate of $1.0 \mathrm{~mL} \mathrm{~min}{ }^{-1}$. The sample injection volume was $1 \mu \mathrm{L}$. The wavelength was set at $225 \mathrm{~nm}$ for the detection.

\subsection{Method validation}

\subsubsection{Resolution and Selectivity}

The resolution (Rs) was calculated as $R s=2\left(t_{2}-t_{1}\right) /\left(w_{1}+w_{2}\right)$ where, $t_{1}, t_{2}$ refer to the retention time of the first and second analytes; $w_{1}$ and $w_{2}$ are the peak widths for the first and second eluting analytes, respectively. The selectivity $(\alpha)$ is the relative retention measured for two adjacent peaks. It was calculated as, $\alpha$ $=\left(t_{2}-t_{0}\right) /\left(t_{1}-t_{0}\right)$ where, $t_{0}$ refers to the retention time of the unretained peak.

\subsubsection{Specificity}

Specificity is the ability to assess unequivocally the analyte in the presence of components, which may beexpected to be present. The specificity of the method was demonstrated by injecting each process-related impurity (Table 1) as well as spiked with Eletriptan sample. The retention time of each impurity was specified.

\subsubsection{Precision (repeatability and reproducibility)}

The precision of an analytical procedure expresses the closeness of agreementbetween a series of measurements from multiple sampling of the same homogeneous sample under prescribed conditions. Precision maybe considered as a repeatability and reproducibility. Repeatability expresses the precision under the same operatingconditions over a short interval of time. Repeatability of the method was studied by spiking impurities with Eletriptanwhich contains $10 \mu \mathrm{g} \mathrm{mL}{ }^{-1}$ concentration for each impurity separately. The precision was examined by analyzing six replicates and the percentage relative standard deviation was calculated for the area and retention time of all the impurities and Eletriptanto demonstrate repeatability. Reproducibility reveals the precision between laboratories. Reproducibility is normally expressed as the lack of the influence on the test results of operational and environmental variables of the analytical method. In order to demonstrate reproducibility of the method the precision experiment was repeated by using different laboratory, different instrument, and different column on another day. The percentage bias of result was calculated between original condition and changed condition.

\subsubsection{Linearity}

The linearity of an analytical procedure is its ability to obtain test results, which are directly proportional tothe concentration of the analyte in the sample. Standard solutions at six different concentration levels ranging from $0.3 \mu \mathrm{gmL}^{-1}$ to $3 \mu \mathrm{g} \mathrm{mL}^{-1}$ were prepared and analyzed in order to demonstrate the linearity for all theimpurities. The regression curve was obtained by plotting peak area versus concentration, using the least squares method andregression equation was obtained for all the impurities. 


\subsubsection{Limit of detection and limit of quantification}

The limit of detection (LOD) of a compound is defined as the lowestconcentration that can be detected. The limit of quantification (LOQ) is the lowest concentration of a compound that can bequantified with acceptable precision and accuracy. The LOD and LOQ for impurities were calculated from the linearity data using formula $3 \sigma / \mathrm{S}$ and $10 \sigma / \mathrm{S}$ respectively. The six points linearity curve obtained in linearity study in the range of $0.3 \mu \mathrm{g} \mathrm{mL}^{-1}$ to $3 \mu \mathrm{g} \mathrm{mL}^{-1}$ for each impurity was used to determined residual standard deviation $(\sigma)$ and slope (S).

\subsubsection{Accuracy}

The accuracy of an analytical procedure expresses the closeness of agreement between the value, which isaccepted either as a conventional true value or an accepted reference value and the value found. The standard addition andrecovery experiments were conducted to demonstrate accuracy of the method. The study was carried out in triplicate for the determination of recovery at 50,100 and $150 \%$ concentration of specification level for all the impurities. The peak area for eachimpurity was determined and recovery was calculated from the peak area of impurity standard solution at the same concentrationlevel.

\subsubsection{Robustness}

The robustness of an analytical procedure is the measure of its capacity to remain unaffected by small, butdeliberate, variations in method parameters and provides an indication of its reliability during normal usage. The robustnessof a method was demonstrated by altering experimental conditions and chromatographic resolution between Eletriptan hydrobromide(ETN) and its closest eluting impurity i.e. Impurity-B was used to evaluate robustness. The deliberate changes were made in thechromatographic conditions, viz. change in flow rate by $\pm 0.2 \mathrm{~mL} \mathrm{~min}^{-1}$ and change in the column temperature $\pm 5^{\circ} \mathrm{C}$.

\subsubsection{Solution stability}

Chromatographic analyses typically are performed by using auto samplers and overnight runs. As such,it is important to verify that the sample is stable in the solution prescribed by the method for periods encompassing the expectedanalysis duration period. Stability of test solution at analyte concentration was studied by keeping the solution in tightly cappedvolumetric flask at room temperature on a laboratory bench for $24 \mathrm{~h}$. The purity of the test solution was checked for $6 \mathrm{~h}$ interval.

\subsection{Quantification of process related impurities}

The relative response factors for process related impurities were determined from the solution containing Eletriptan and allthe process related impurities in known amounts i.e. $5 \mu \mathrm{g} \mathrm{mL}{ }^{-1}$. The accurate weight percentage of the impurity present in Eletriptan sample was calculated using its RRF value and peak response. The percentage area obtained from the areanormalized method was divided by corresponding RRF value to determine accurate amount of each impurity.

\subsection{Method development}

\section{Results and discussion}

The present study is aimed at developing anUPLCsystem capable of eluting and resolving Eletriptan and its synthesis relatedimpurities. Structure of impurities and Eletriptanare shown in Table 1. The selection of wavelength becomes a challenging task to detect all the compounds at single wavelength since the UV profile of all the compounds is different. UV spectra of all thecompounds were studied by scanning them between $190 \mathrm{~nm}$ to $400 \mathrm{~nm}$ (Fig. 1). It can be seen that it is difficult to detect all thecompounds at single wavelength with equal response. However, 220 or $225 \mathrm{~nm}$ wavelength can be selected as common wavelength for detection. During the experiments, it has been observed that baseline stability, mobile phase interference and noise level weremore desirable at $225 \mathrm{~nm}$ than $220 \mathrm{~nm}$. Moreover, theadequate detection and quantification limit were found for all theimpurities at $225 \mathrm{~nm}$ therefore, $225 \mathrm{~nm}$ was finalized as commonwavelength for detection. Additionally, relative response factor ofall the impurities was evaluated for accurate determination.The method development was initiated with water :acetonitrile or methanol $(90: 10 \mathrm{v} / \mathrm{v})$ as a mobile phase in isocraticmode using Acuity UPLC BEH C18 $(100 \times 2.1 \mathrm{~mm}, 1.7 \mu \mathrm{m})$ column at $30^{\circ} \mathrm{C}$. Under this condition results were notsatisfactory. Water was replaced by 0.01 Mmonobasic potassium phosphate inwater, whichwas slightly improved peak shape but not the resolution. After the addition of triethylamine in buffer with $\mathrm{pH} 6.8$ using $\mathrm{H}_{3} \mathrm{PO}_{4}$, which enhanced the peak shape and all the impurities were well separated. This much difference in the retention time isindicative of differences in the polarity of the each compound.Several, permutationsand combination of buffer, acetonitrile and methanol have been scanned to finalize thecomponents of mobile phase. It has been observed that $55: 38: 7$ (Buffer, acetonitrile and methanol) gave better result than any other tested combinations. Finally, isocratic program of $55: 38: 7$ (Buffer, acetonitrile and methanol), with flow rate of $1.0 \mathrm{~mL} \mathrm{~min}^{-1}$ was found to be optimal. The representative chromatogram isshown in Fig. 2 and resolution and selectivity data are summarized 
in Table 2. UPLC column HSS T3 C18 (100 x $2.1 \mathrm{~mm}, 1.8 \mu \mathrm{m})$ and different buffers were also tried but the results were not encouraging.

Fig. 1 UV Spectra of Eletriptan and its impurities

ETN

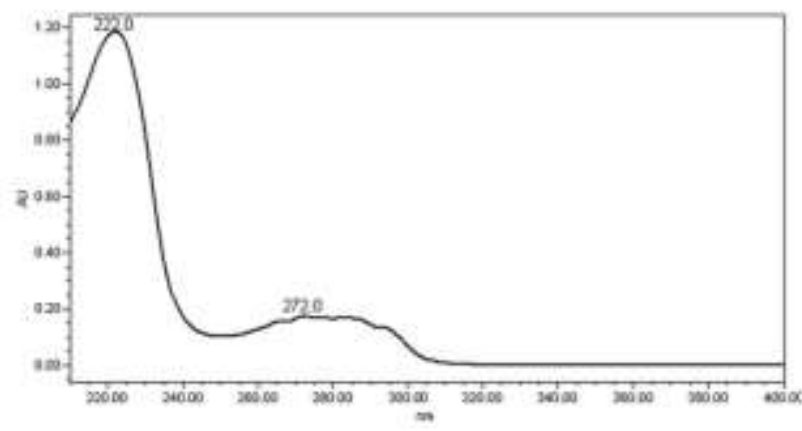

Imp-A

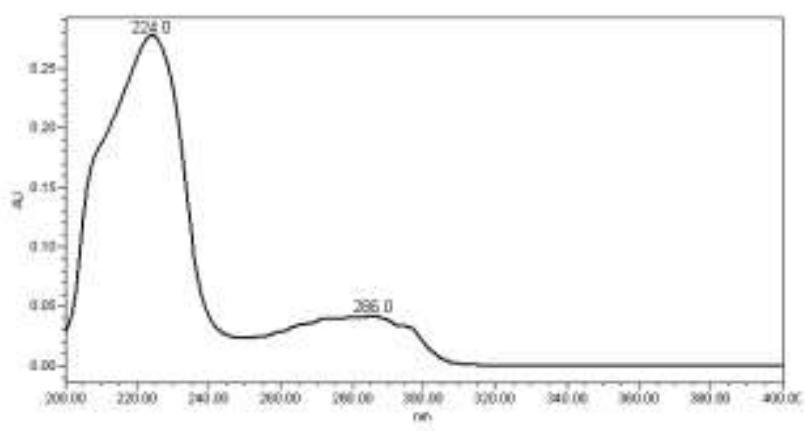

Imp-B

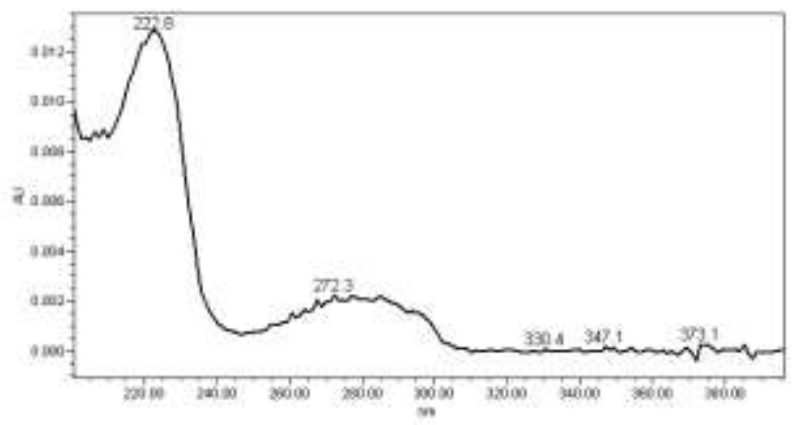

Imp-C

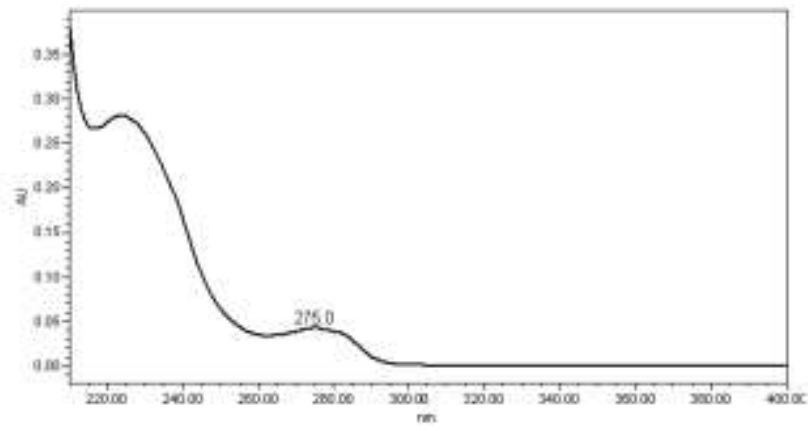

Imp-D 


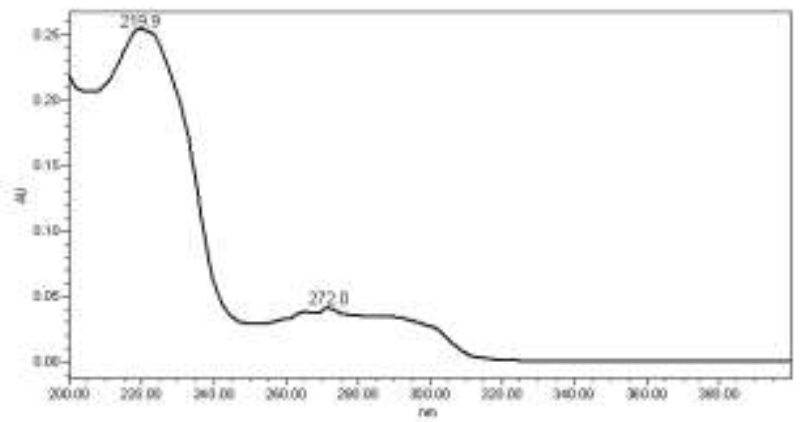

Fig. 2 UPLC finalized condition chromatogram

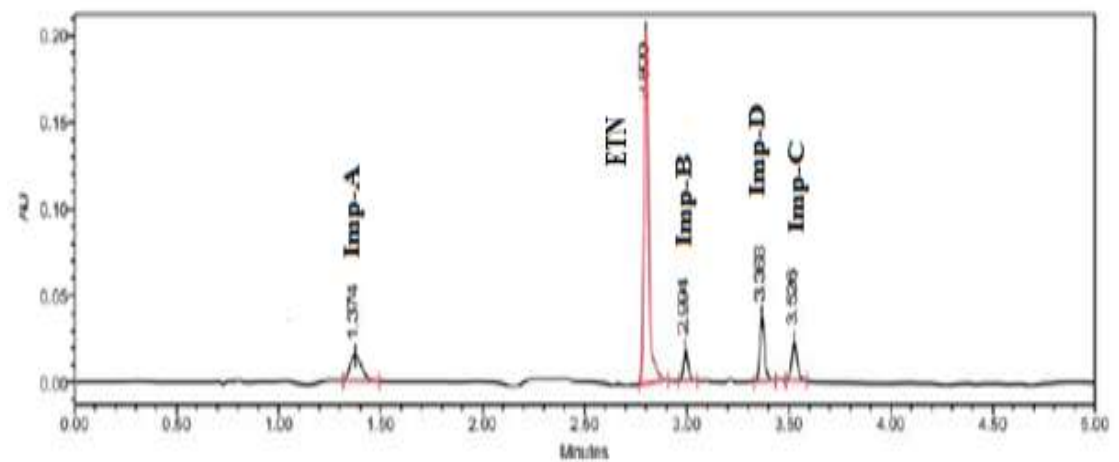

Table 1. Structure of Eletriptan and its process related impurities

\begin{tabular}{|c|c|c|}
\hline Name & Structure & Details \\
\hline Imp-A & & $\begin{array}{c}\text { (R,E)-3-((1-methylpyrrolidin-2-yl)methyl)-5- } \\
\text { (2-(phenylsulfonyl)vinyl)-1H-indole } \\
\text { hydrobromide } \\
\text { Chemical Formula: } \mathrm{C}_{22} \mathrm{H}_{25} \mathrm{BrN}_{2} \mathrm{O}_{2} \mathrm{~S} \\
\text { Molecular Weight: } 461.42\end{array}$ \\
\hline Imp-B & & $\begin{array}{l}\text { (R)-5-ethyl-3-((1-methylpyrrolidin-2- } \\
\text { yl)methyl)-1H-indole } \\
\text { Chemical Formula: } \mathrm{C}_{16} \mathrm{H}_{22} \mathrm{~N}_{2} \\
\text { Molecular Weight: } 242.36\end{array}$ \\
\hline Imp-C & & $\begin{array}{c}\text { (R,E)-3-((1-methylpyrrolidin-2-yl)methyl)-1- } \\
\text { (2-(phenylsulfonyl)ethyl)-5-(2- } \\
\text { (phenylsulfonyl)vinyl)-1H-indole } \\
\text { Chemical Formula: } \mathrm{C}_{30} \mathrm{H}_{32} \mathrm{~N}_{2} \mathrm{O}_{4} \mathrm{~S}_{2} \\
\text { Molecular Weight: } 548.72\end{array}$ \\
\hline Imp-D & & $\begin{array}{c}\text { (R)-3-((1-methylpyrrolidin-2-yl)methyl)-1,5- } \\
\text { bis(2-(phenylsulfonyl)ethyl)-1H-indole } \\
\text { Chemical Formula: } \mathrm{C}_{30} \mathrm{H}_{34} \mathrm{~N}_{2} \mathrm{O}_{4} \mathrm{~S}_{2} \\
\text { Molecular Weight: } 550.73\end{array}$ \\
\hline
\end{tabular}




\begin{tabular}{|c|c|c|}
\hline \multirow{2}{*}{ ETN } & & (R)-3-((1-methylpyrrolidin-2-yl)methyl)-5-(2- \\
& (phenylsulfonyl)ethyl)-1H-indole \\
& hydrobromide \\
& Chemical Formula: $\mathrm{C}_{22} \mathrm{H}_{27} \mathrm{BrN}_{2} \mathrm{O}_{2} \mathrm{~S}$ \\
Molecular Weight: 463.43
\end{tabular}

Table 2. Results of selectivity and resolution

\begin{tabular}{|c|c|c|c|}
\hline Name & Retention time & Selectivity & Resolution \\
\hline Impurity A & 1.374 & --- & -- \\
\hline ETN & 2.800 & 2.63 & 19.6 \\
\hline Impurity B & 2.994 & 1.08 & 4.88 \\
\hline Impurity D & 3.368 & 1.15 & 8.93 \\
\hline Impurity C & 3.526 & 1.06 & 3.45 \\
\hline
\end{tabular}

\subsection{Result of relative response factor}

The relative response factor (RRF) of Impurity-A, Impurity-B, Impurity-C, and Impurity-D with respect to Eletriptan werefound to be $0.94,0.96,0.92$ and 0.90 respectively.

\subsection{Validation results of the method}

Eletriptanand its related impurities were well resolved with no interference from the blank and mobile phase. In the precisionstudy, the percentage relative standard deviation (RSD) of six replicates was found less than $0.1 \%$ for retention time and $2.0 \%$ for peak area of all the impurities and Eletriptan, indicating good repeatability of the method (Table 3). The results of the reproducibility study under a different set of conditions are also in the same order of magnitude. The percentage bias between two different sets of conditions for retention time and peak area was within \pm 0.36 and \pm 0.64 respectively for all the impurities (Table 3 ), indicates that method is rugged for its intended use. The described method was linear in the range of $0.3 \mu \mathrm{gmL}^{-1}$ to $3 \mu \mathrm{g}$ $\mathrm{mL}^{-1}$ of each impurity, which was demonstrated acceptability of the method for the quantitative determination in that range. The value of slope, intercept and correlation coefficient for each impurity are shown in Table 4.The LOD and LOQ concentration were estimated for all the impurities and are in the range of 0.16 to $0.24 \mu \mathrm{gL}^{-1}$ and 0.49 to $0.74 \mu \mathrm{gmL}^{-1}$ respectively (Table 4). The method showed excellent recovery at three different studied concentrations, 50,100 and 150\% of specification level for all the impurities (Table 5). The mean recoveries of all the impurities were found to be in the range of 98 to $102 \%$. The chromatographic resolution between closest eluting impurity i.e. Impurity-B and Eletriptanwas used to evaluate the method robustness under modified conditions. There was no significant change in resolution under all separation conditions tested (Table 6), demonstrating sufficient robustness. No significant change in the purity of Eletriptanwas observed during solution stability experiments. Thus, Eletriptantest solution was found to be stable for at least $24 \mathrm{~h}$.

Table 3. Results of repeatability and reproducibility study

\begin{tabular}{|c|c|c|c|c|c|c|c|c|c|c|}
\hline \multirow[b]{2}{*}{ Compound } & \multicolumn{2}{|c|}{ Original condition } & \multicolumn{2}{|c|}{$\begin{array}{l}\text { Different } \\
\text { condition }\end{array}$} & \multirow[b]{2}{*}{$\%$ Bias } & \multicolumn{2}{|c|}{$\begin{array}{c}\text { Original } \\
\text { condition }\end{array}$} & \multicolumn{2}{|c|}{$\begin{array}{l}\text { Different } \\
\text { condition }\end{array}$} & \multirow[b]{2}{*}{$\%$ Bias } \\
\hline & $\begin{array}{c}\text { Average } \\
\text { retention } \\
\text { time }\end{array}$ & $\begin{array}{c}\text { \% RSD } \\
(n=6)\end{array}$ & $\begin{array}{c}\text { Average } \\
\text { retention } \\
\text { time }\end{array}$ & $\begin{array}{c}\text { \% RSD } \\
(n=6)\end{array}$ & & $\begin{array}{c}\text { Average } \\
\text { Peak } \\
\text { area } \\
\end{array}$ & $\begin{array}{c}\text { \% RSD } \\
(n=6)\end{array}$ & $\begin{array}{c}\text { Average } \\
\text { Peak } \\
\text { area } \\
\end{array}$ & $\begin{array}{c}\text { \% RSD } \\
(\mathrm{n}=6)\end{array}$ & \\
\hline Impurity A & 1.36 & 0.13 & 1.36 & 0.10 & 0.0 & 11985 & 0.89 & 12025 & 0.65 & 0.34 \\
\hline Impurity B & 3.01 & 0.02 & 3.02 & 0.18 & 0.33 & 3966 & 0.20 & 3967 & 0.97 & 0.03 \\
\hline Impurity $\mathrm{C}$ & 3.53 & 0.02 & 3.53 & 0.03 & 0.0 & 4954 & 0.95 & 4962 & 0.24 & 0.16 \\
\hline Impurity D & 3.38 & 0.02 & 3.39 & 0.09 & 0.30 & 11773 & 1.76 & 11806 & 0.79 & 0.28 \\
\hline ETN & 2.81 & 0.04 & 2.82 & 0.10 & 0.36 & 5744324 & 0.90 & 5707314 & 0.19 & -0.64 \\
\hline
\end{tabular}

Table 4. Results of linearity and LOD, LOQ study of impurities

\begin{tabular}{|c|c|c|c|c|}
\hline \multirow{2}{*}{ Parameter } & \multicolumn{4}{|c|}{ Result } \\
\cline { 2 - 5 } & Impurity A & Impurity B & Impurity C & Impurity D \\
\hline Correlation coefficient & 0.999 & 0.998 & 0.999 & 0.999 \\
\hline Y-Intercept & 302.04 & -374.09 & -165.57 & -78.68 \\
\hline Slope & 6667.2 & 3318 & 4803.6 & 5809.1 \\
\hline $\begin{array}{c}\text { Residual standard } \\
\text { deviation }\end{array}$ & 327.24 & 245.87 & 251.30 & 297.88 \\
\hline LOD $/ \mu \mathrm{g} \mathrm{mL}^{-1}$ & 0.16 & 0.24 & 0.17 & 0.17 \\
\hline LOQ $/ \mu \mathrm{g} \mathrm{mL}^{-1}$ & 0.49 & 0.74 & 0.52 & 0.51 \\
\hline
\end{tabular}


Table 5. Results of accuracy study of impurities

\begin{tabular}{|c|c|c|c|}
\hline Level (\%) & Added / ng $\mathbf{~ L L}^{-1}$ & Recovered / ng $\mathbf{~ m}^{-1}$ & \% Recovery \\
\hline Impurity A (n=3) & 1000 & 999.5 & 99.95 \\
\hline 50 & 2000 & 1997 & 99.85 \\
\hline 100 & 3000 & 3008.7 & 100.29 \\
\hline 150 & 1000 & 984.4 & 98.44 \\
\hline Impurity B (n=3) & 1976.8 & 98.84 \\
\hline 50 & 3000 & 2973.6 & 99.12 \\
\hline 100 & 1000 & 1001.9 & 100.19 \\
\hline 150 & 2000 & 2000.2 & 100.01 \\
\hline Impurity C (n=3) & 3000 & 2985.9 & 99.53 \\
\hline 50 & 1000 & 1002.1 & 100.21 \\
\hline 100 & 2000 & 1997 & 99.85 \\
\hline 150 & 3000 & 3007.2 & 100.24 \\
\hline
\end{tabular}

Table 6. Results of robustness study

\begin{tabular}{|c|c|}
\hline Parameter & Resolution between ETN and Impurity B (n=3) \\
\hline Flow rate $\mathrm{mL} \mathrm{min}^{-1}$ & \\
\hline 0.8 & 5.08 \\
\hline 1.0 & 4.85 \\
\hline 1.2 & 4.65 \\
\hline 25 & \\
\hline 30 & 4.94 \\
\hline 35 & 4.85 \\
\hline Column Temperature $^{\circ} \mathrm{C}$ & 4.76 \\
\hline Concentration of triethylmine $(\%)$ & \\
\hline 0.01 & 4.83 \\
\hline 0.02 & 4.85 \\
\hline 0.03 & 4.84 \\
\hline
\end{tabular}

\subsection{Degradation study}

Degradation studies were performed to demonstrate selectivity and stability-indicating capability of the proposed method. The sample was exposed to acid $\left(0.1 \mathrm{~N} \mathrm{HCl}, 80^{\circ} \mathrm{C}\right.$ for 48 hours $)$, base $\left(0.1 \mathrm{~N} \mathrm{NaOH}, 80^{\circ} \mathrm{C}\right.$ for 48 hours), oxidation $\left(3 \% \mathrm{H}_{2} \mathrm{O}_{2}\right.$, Room temperature for 24 hours), thermal solid state $\left(60^{\circ} \mathrm{C}\right.$ for 7 days), thermal liquid state $\left(80^{\circ} \mathrm{C}\right.$ for 6 Hours), humidity $\left(75 \% \mathrm{RH}, 40^{\circ} \mathrm{C}, 7\right.$ Days) and photolytic (1.2 million lux hours, 200 $\mathrm{w} . \mathrm{hr} / \mathrm{m}^{2}, 18$ days) degradation conditions. Samples were withdrawn at appropriate times and subjected to UPLC analysis after suitable dilutionto evaluate the ability of the proposed method to separate Eletriptan from its degradation products. Photodiode array detector was employed to check and ensure the homogeneity and purity of Eletriptan peak in all the stressed sample solutions.

The degradation study revealed that Eletriptanwas sensitive to peroxide and light compared to other degradation conditions. Eletriptan hydrobromide (ETN) was degraded during oxidation $\left(3 \% \mathrm{H}_{2} \mathrm{O}_{2}\right.$, Room temperature for 24 hours) at around 6\% level and it was degraded during light exposure (1.2 million lux hours, $200 \mathrm{w} \cdot \mathrm{hr} / \mathrm{m}^{2}, 18$ days) at around $9 \%$ level. The API and its impurities were treated with different degradation conditions including acid, base, peroxide, photolytic, humidity and thermal degradations. The degradation results were shown in Table 7. 
Table 7.Forced degradation results of ETN

\begin{tabular}{|c|c|c|c|c|c|}
\hline Degradation conditions & $\%$ Imp-A & $\%$ Imp-B & $\%$ Imp-C & $\%$ Imp-D & $\begin{array}{c}\text { \% Major } \\
\text { degradation } \\
\text { product } \\
\end{array}$ \\
\hline $\begin{array}{c}\text { Acid treatment } \\
\left(0.1 \mathrm{~N} \mathrm{HCl}, 80^{\circ} \mathrm{C} \text { for } 48 \text { hours }\right)\end{array}$ & 0.04 & 0.08 & --- & 0.04 & 0.30 \\
\hline $\begin{array}{c}\text { Base treatment } \\
\left(0.1 \mathrm{~N} \mathrm{NaOH}, 80^{\circ} \mathrm{C} \text { for } 48 \text { hours }\right)\end{array}$ & --- & 0.18 & --- & 0.04 & 0.17 \\
\hline $\begin{array}{c}\mathrm{H}_{2} \mathrm{O}_{2} \text { treatment } \\
\left(3 \% \mathrm{H}_{2} \mathrm{O}_{2}, \text { Room temperature }\right. \\
\text { for } 24 \text { hours })\end{array}$ & --- & 0.14 & --- & 0.01 & 6.40 \\
\hline $\begin{array}{c}\text { Thermal (liquid state) - } \\
80^{\circ} \mathrm{C} \text { for } 6 \text { Hours }\end{array}$ & --- & 0.13 & --- & 0.01 & 0.08 \\
\hline $\begin{array}{l}\text { Thermal (solid state) - } \\
60^{\circ} \mathrm{C} \text { for } 7 \text { days }\end{array}$ & 0.01 & 0.14 & 0.01 & 0.03 & 0.14 \\
\hline $\begin{array}{c}\text { Humidity-75\% RH, } 40{ }^{\circ} \mathrm{C}, 7 \\
\text { days }\end{array}$ & --- & 0.16 & --- & 0.03 & 0.09 \\
\hline $\begin{array}{l}\text { Photolytic- } 1.2 \text { million lux hours, } \\
200 \mathrm{Wh} / \mathrm{m}^{2}, 18 \text { days }\end{array}$ & --- & 0.09 & 0.07 & 0.04 & 8.77 \\
\hline
\end{tabular}

The degradation of API in acid, base, thermal and humidity conditions was observed to be lower. Spectral purity of API and its impurities in the chromatogram of all the exposed samples are obtained from PDA and found to be spectrally pure, indicating that there was no co-elution of peak at the retention time of the respective known and unknown impurities. The max plot chromatogram of degradation sample was also checked to ensure that no degradation peak is missed due to use of wavelength of $225 \mathrm{~nm}$.

\subsection{Analysis of bulk drug}

To demonstrate applicability of the developed method several different lots of Eletriptanbulk drug have been tested. Sampleof Eletriptanwas prepared at test concentration i. e. $1.0 \mathrm{mg} \mathrm{mL}^{-1}$ in diluent (methanol) and injected inequilibrated UPLC system after two run of diluent. Area percentage of impurities was obtained by area normalized method and the actual percentage of each known impurity was calculated by dividing area percentage with its corresponding RRF value. The results of five representative lots of Eletriptanbulk drug are presented in Table 8.

Table 8. Results of analysis of different lots of Eletriptan bulk drug

\begin{tabular}{|c|c|c|c|c|c|}
\hline \multirow{2}{*}{ Name } & \multicolumn{5}{|c|}{ Content of impurities in different lots (\%) } \\
\cline { 2 - 6 } & ETN 001 & ETN 002 & ETN 003 & ETN 004 & ETN 005 \\
\hline Impurity A & 0.12 & 0.17 & 0.11 & 0.09 & 0.19 \\
\hline Impurity B & BQL & 0.05 & BQL & BQL & BQL \\
\hline Impurity C & 0.04 & 0.07 & BQL & BQL & 0.04 \\
\hline Impurity D & 0.05 & 0.11 & 0.06 & BQL & 0.07 \\
\hline Unknown impurity & --- & 0.04 & --- & --- & 0.05 \\
\hline Eletriptan & 99.79 & 99.56 & 99.83 & 99.91 & 99.65 \\
\hline \multicolumn{7}{|c|}{ BQL: Below Quantification Level } \\
\hline
\end{tabular}

\section{Conclusion}

A simple, rapid, suitable, precise, accurate and stability indicating UPLC method has been developed for the determination of the process relatedimpurities in Eletriptanbulk drug. All the impurities were well resolved within $5 \mathrm{~min}$ and resolution of the closest eluting peaks was more than 4.8. The developed method was completely validated with respect to specificity, system suitability, linearity, limit of detection and quantitation, accuracy, precision, robustness and solution stability. The result of validation showed satisfactory data for all the parameters tested. The developed method can be used for the determination ofprocess related impurities (Impurity-A, Impurity-B, Impurity-C and Impurity-D) in Eletriptanin the bulk drug substance.

\section{Acknowledgements}

The authors wish to thank the management of Department of chemistry, Adhiyamaan Engineering College, Hosur, Tamil Nadu, India and Jiangsu Pharma limited (China) for supporting this work.

\section{References}


[1] Cooper, J. D. H. ; Muirhead, D. C. ; Taylor, J. E., Determination of Eletriptan in plasma and saliva using automated sequential trace enrichment of dialyzate and high performance liquid chromatography, Journal of Pharmaceutical and Biomedical Analysis (1999), 21(4), 787-796.

[2] Zecevic, Mira; Jocic, Biljana; Agatonovic-Kustrin, Snezana; Zivanovic, Ljiljana, Validation of an HPLC method for the simultaneous determination of eletriptan and UK 120.413, Journal of the Serbian Chemical Society (2006), 71(11), 1195-1205.

[3] Suneetha, D.; Rao, A. Lakshmana, RP-HPLC method for the estimation of eletriptan in pharmaceutical dosage forms, International Journal of Chemical, Environmental and Pharmaceutical Research (2010), 1(2), 95-99.

[4] Kumar, A. Phani; Ganesh, V. R. L.; Prasad, K. Hari; Hariharakrishnan, V. S.; Dubey, P. K.; Rao, B. Venugopala , HPLC method for the enantiomeric purity of eletriptan hydrobromide, Asian Journal of Chemistry (2011), 23(4), 1621-1624.

[5] El-Bagary, Ramzia I.; Mohammed, Nashwah G.; Nasr, Heba A, Two chromatographic methods for the determination of some antimigraine drugs, Analytical Chemistry Insights (2012), 7, 13-21.

[6] KumaraSwamy, G.; Kumar, J. M. R.; Sheshagiri Rao, J. V. L. N., Development and validation of RP - HPLC method for the estimation of Eletriptan hydrobromide in bulk and tablet dosage form, Journal of Pharmacy Research (2012), 5(1), 538-540.

[7] Sagirli, Olcay; Onal, Armagan; Sensoy, Demet, LC assay of eletriptan in tablets and in vitro dissolution studies, Chromatographia (2008), 68(3/4), 269-273.

[8] Jocic, Biljana; Zecevic, Mira; Zivanovic, Ljiljana; Protic, Ana; Jadranin, Milka; Vajs, Vlatka, Study of forced degradation behavior of Eletriptan hydrobromide by LC and LC-MS and development of stabilityindicating method, Journal of Pharmaceutical and Biomedical Analysis (2009), 50(4), 622-629.

[9] Ponnuru, Venkata Suresh; Challa, B. R.; Nadendla, Ramarao, Quantitative analysis of eletriptan in human plasma by HPLC-MS/MS and its application to pharmacokinetic study, Analytical and Bioanalytical Chemistry (2011), 401(8), 2539-2548.

[10] Speir, J. Paul; Perkins, George; Berg, Christian; Pullen, Frank, Fast, generic gradient high performance liquid chromatography coupled to Fourier transform ion cyclotron resonance mass spectrometry for the accurate mass analysis of mixtures, Rapid Communications in Mass Spectrometry (2000), 14(20), 1937-1942.

[11] Saka, Cafer, Review of Analytical Methods for Identification and Determination of Triptans, Critical Reviews in Analytical Chemistry (2009), 39(1), 32-42.

[12] El-Bagary, Ramzia I.; Mohammed, Nashwah G.; Nasr, Heba A., Fluorimetric and colorimetric methods for the determination of some antimigraine drugs, Journal of Chemical and Pharmaceutical Research (2011), 3(4), 304-314.

[13] Onal, Armagan, Spectrophotometric and spectrofluorimetric determination of some drugs containing secondary amino group in bulk drug and dosage forms via derivatization with 7-chloro-4-nitrobenzofurazon, Quimica Nova (2011), 34(4), 677-682.

[14] Kumara Swamy G, JMR Kumar, JVLN Sheshagiri Rao, U Ashok Kumar, E VinayaSnehalatha, Spectrophotometric Method for the Estimation of Eletriptan Hydrobromide in Pure and Tablet Dosage Forms, International Journal of Chemical and Analytical Science, Vol 2, No $8 \quad$ (2011).

[15] L. Rajasekhar, Venkatamahesh R, PS. Satyanarayana, Development and Validation of Derivative Spectrophotometric Method for Quantitative Estimation of Eletriptan Hydrobromide in Bulk and Pharmaceutical Dosage Forms, International Journal of Research in Pharmaceutical and Biomedical Sciences, Vol. 2 (3), 2011.

[16] P. Sunitha, CH. Jhansirani, B. Kavitha, N. Sirisha and A. Pavani, method development and validation of eletriptan hydrobromide tablets by uv-visible spectrophotometric method, International Journal Of Pharmaceutical, Chemical And Biological Sciences, 2012, 2(4), 427-430

[17] Ramzia I. El-Bagary, Nashwah G. Mohammed, Heba A. Nasr, Two Chromatographic Methods for the Determination of Some Antimigraine Drugs, Analytical Chemistry Insights 2012:7 13-21 